\section{ВоЗМОЖНОСТИ НУТРИТИВНОЙ ПОДДЕРЖКИ ПРОБИОТИКОМ «БИОВЕСТИН» В БОРЬБЕ С ГАСТ- РОИНТЕСТИНАЛЬНЫМИ ОСЛОЖ- НЕНИЯМИ У ОНКОЛОГИЧЕСКИХ ПАЦИЕНТОВ В ПЕРИОД ПРОВЕДЕНИЯ ХИМИОТЕРАПИИ}

Войщищкий В.Е., Лебедева В.А., Ткачук О.А., ФГБОУ ВО «Новосибирский государственный медицинский университет» Минздрава России

\section{АННОТАЦИЯ}

Заболеваемость онкологической патологией в России и во всем мире неуклонно растет, не снижается и уровень смертности. Выявляется большое количество местнораспространенных и запущенных случаев рака различных локализаций. Лечение данных форм требует проведения полихимиотерапии (ПХТ). В исследование включены 52 пациента с онкологической патологией различных локализаций (голова и шея, желудок, толстая кишка), им проводилась адъювантная химиотерапия по схемам PF, TPF и FOLFOX, в состав которых входит инфузия 5-фторурацила в течение $2-5$ дней. В ходе исследования анализировалась гастроинтестинальная токсичность по СТСАЕ, версия 4.03, 2010 г. Выявлено, что добавление к пище пробиотика «Биовестин» снижает гастроинтестинальную токсичность в 2 раза по сравнению с контрольной группой и на $19 \%$ уменьшает риск прерывания курса ПХТ из-за развития побочных явлений. Таким образом, добавление пробиотика «Биовестин» показало свою эффективность, безопасность и простоту применения в профилактике гастроинтестинальных нарушений у онкологических больных в условиях проведения ПХТ.

Ключевые слова: полихимиотерапия (ПХТ), нутритивная поддержка, «Биовестин», гастроинтестинальная токсичность.

\title{
POSSIBILITIES OF NUTRITIONAL SUPPORT WITH PROBIOTIC «BIOVESTIN» IN THE FIGHT WITH GASTROINTESTINAL COMPLICATIONS IN CANCER PATIENTS DURING CHEMOTHERAPY
}

\author{
Voitsitsky V.E., Lebedeva V.A., Tkachuk O.A., \\ Skuridina I.V. \\ Novosibirsk State Medical University
}

\section{ABSTRACT}

The incidence of oncological pathology in Russia and throughout the world is steadily growing, and the mortality rate is not decreasing either. A large number of locally advanced and neglected cases of cancer of various location are revealed. Treatment of these forms requires polychemotherapy (PCT). The study included 52 patients with oncological pathology of various location: head and neck, stomach, large intestine, they underwent adjuvant chemotherapy according to the PF, TPF and FOLFOX regimens, which include an infusion of 5-fluorouracil for 2-5 days. The study analyzed gastrointestinal toxicity according to CTCAE, version 4.03, 2010.

It was revealed that the addition of the probiotic Biovestin to meal reduces gastrointestinal toxicity by 2 times compared with the control group and reduces the risk of interruption of the PCT course by $19 \%$ due to the development of side effects. Thus, the addition of the probiotic Biovestin has shown its effectiveness, safety and simplicity of use in the prevention of gastrointestinal disorders in cancer patients under conditions of PCT.

Keywords: polychemotherapy (PCT), nutritional support, Biovestin, gastrointestinal toxicity.

Corresponding author

Tkachuk Olga Anatolyevna: Novosibirsk State Medical University, 52, Krasny Prospect, Novosibirsk, 630091, Russia.

E-mail: naiz@rambler.ru

(с ФГБОУ ВО НГМУ Минздрава России, 2021

\section{ВВЕДЕНИЕ}

Нарушение функций пищеварительной системы является самым частым нежелательным явлением, связанным с лекарственным лечением (хи- миотерапией, гормонотерапией, иммунотерапией, таргетной терапией). Проведение цитостатического лечения, особенно с использованием высокоинтенсивных режимов химиотерапии, со- 
провождается в 75 \% случаев развитием токсического энтероколита и в 63 \% - стоматита различной степени выраженности [1]. Нарушения стула сопровождают как химиотерапию, так и гормонотерапию. Симптомами поражения кишечника после химиотерапии являются: возникновение болей в животе спазматического характера, появление урчания и вздутия живота, запоров или поносов, а также неустойчивого стула чередования запоров с диареей [2]. При этом позывы к опорожнению кишечника часто бывают болезненными. Иногда в каловых массах наблюдается слизь или примесь крови. В этом состоянии больной испытывает чувство вялости и слабости, иногда наблюдается повышение общей температуры тела. Диарея после химиотерапии возникает вследствие дисбактериоза в кишечнике, вызванного действием химиотерапевтических препаратов [3]. Также причиной диареи является поражение периферической нервной системы, проявляющееся полинейропатией. Диарея нередко является побочным эффектом применения антиэметогенных препаратов, которые применяются для купирования тошноты и рвоты во время курсов полихимиотерапии. Она вызывает нутритивную недостаточность в организме онкологического пациента [4], приводящую к усилению медикаментозной нагрузки, увеличению длительности пребывания больного в стационаре и, как следствие, повышению экономических затрат на лечение.

Известно, что коррекция статуса питания способствует улучшению прогноза выживаемости, снижению риска послеоперационных осложнений и токсичности химиотерапии, повышению качества и продолжительности жизни. Клинические проявления энтероколита вносят свой вклад в формирование хронического болевого синдрома, существенно снижающего качество жизни больных и требуют дополнительной фармакотерапии, нередко становясь причиной нарушения режима введения химиотерапевтических препаратов [5]. Изменение кишечной микрофлоры нередко обделено вниманием врача-онколога [6]. Однако возникший дисбактериоз снижает эффективность пищеварения, создает условия для дополнительной нагрузки на детоксикационные системы печени, способствует развитию вздутия живота и процессов гниения в кишечнике. Выраженные симптомы энтероколита, ректита, ректосигмоидита могут стать причиной прерывания курса химиотерапии, что влечет за собой снижение эффективности лечения [7]. При умеренном проявлении симптомы поражения кишечника существенно ухудшают аппетит, снижают физическую толерантность к легким физическим нагрузкам, что ограничивает возможность пациента выполнить такие рекомендации врача, как правильное питание и прогулки на свежем воздухе. В итоге нарушение работы кишечника может стать причиной низкой эффективности противоопухолевого лечения [8].

Клиническая эффективность некоторых продуктов питания позволяет рассматривать их как средства, корригирующие нежелательные побочные явления вследствие фармакотерапии или повышающие эффективность лечебного воздействия химиотерапевтических лекарственных препаратов [9]. К таким продуктам питания относятся биологически активные добавки, сочетающие в себе активные формы фармакопейных штаммов бифидобактерий, факторы роста и продукты метаболизма бифидобактерий имеют небольшую кислотность, соответствующую кисломолочным продуктам. Эти вопросы легли в основу работы.

В настоящее время остро развивается ситуация с эпидемией COVID-19 в мире, поэтому нельзя не коснуться изменений, происходящих в лечении онкологических больных. Особые условия работы, продиктованные пандемией, заставляют экспертов пересмотреть подход к лекарственной терапии онкологических пациентов как минимум для того, чтобы минимизировать число визитов в онкологическое отделение для лекарственной терапии, но при этом не ухудшить отдаленные результаты. Таким образом, в условиях пандемии необходимо особенно тщательно соблюдать возможности профилактики и лечения осложнений ПХТ [10].

\section{ЦЕЛЬ ИССЛЕДОВАНИЯ}

Определить возможности профилактики возникновения гастроинтестинальной токсичности во время проведения ПХТ у онкологических больных путем перорального применения биологически активной добавки к пище, содержащей в себе активные формы фармакопейных штаммов бифидобактерий - «Биовестин А».

\section{МАТЕРИАЛЫ И МЕТОДЫ}

Исследование проводилось на базе радиологического отделения ГБУЗ НСО «Новосибирский областной клинический онкологический диспансер». Все пациенты проходили комплексное лечение в 2019-2020 гг. В ходе исследования проведен анализ введения в пищевой рацион пробиотического продукта «Биовестин A» 
Таблица 1

Распределение пациентов по возрастным группам

\begin{tabular}{lll}
\hline Показатель & Группа 1 & Группа 2 \\
\hline Возраст пациентов, лет & $57,2 \pm 3,41$ & $61,1 \pm 5,19$ \\
Количество пациентов & 26 & 26 \\
\hline
\end{tabular}

26 больных со злокачественными новообразованиями различных локализаций (голова и шея, желудок, толстая кишка), которым проводилась адъювантная химиотерапия по схемам PF, TPF и FOLFOX, включавшим постоянную инфузию 5-фторурацила в течение $2-5$ сут [1115]. Контрольная группа состояла из 26 больных со злокачественными опухолями аналогичной локализации и получала адъювантную химиотерапию по аналогичным схемам без пробиотических продуктов в диете. Средний возраст пациентов группы исследования составил 57,2 \pm 3,41 года, группы контроля $61,1 \pm 5,19$ года. Медиана возраста пациентов - 61 год, распределение по возрасту - согласно табл. 1.

Биологически активную добавку к пище «Биовестин» пациенты принимали во время инфузии 5-фторурацила: по 12 мл 2 раза в день за 30 мин до еды - весь период инфузии препарата, с последующим переходом на прием 6 мл 2 раза в день - в межкурсовой период до начала следующего курса инфузии фторурацила. В последующие курсы химиотерапии дозировка «Биовестина» аналогична.

Проведен анализ гастроинтестинальной токсичности первого курса химиотерапии по критериям СТСАЕ, версия 4.03, 2010 г. Шкала отражает 0-4 степени токсичности по следующим параметрам: анорексия, ухудшение аппетита, неопухолевый асцит, диарея, эзофагит, сухость ротовой полости, изжога, фистула кишки, желудочно-кишечные кровотечения, тошнота, рвота, тонкокишечная непроходимость, боль в животе, стоматит, гастрит, проктит, нарушение вкуса [16]. Показатели оценивались ежедневно в первые 7 дней каждого курса ПХТ.

\section{РЕЗУЛЬТАТЫ И ОБСУЖДЕНИЕ}

В ходе наблюдения выявлены следующие показатели гастроинтестинальной токсичности: анорексия, ухудшение аппетита, диарея, боль в животе, стоматит. Максимальная степень токсичности и количество случаев выявления каждого состояния представлены в табл. 2.

Согласно исследованию, в обеих группах наблюдались токсические явления, но в группе пациентов, где назначался «Биовестин А», признаки гастроинтестинальной токсичности встречались реже и имели легкое клиническое течение. Ни у одного пациента из группы исследования не наблюдалось случаев 3-4-й степени токсичности. Имеющие место признаки гастроинтестинальной токсичности ПХТ носили легкий характер и медикаментозно корригировались. Необходимости прервать рекомендуемый химиотерапевтический режим не возникло. У пациентов контрольной группы необходимость прервать курс ПХТ по причине выраженности диареи, болевого синдрома, стоматита возникла у 5 пациентов, что составило 19,2 \% от количества больных в группе исследования (табл. 3).

\section{ЗАКЛЮЧЕНИЕ}

Дополнение диеты больных злокачественными опухолями головы и шеи, желудка, толстой кишки, получающих адъювантную химиотерапию

Таблица 2

Распределение пациентов по гастроинтестинальной токсичности во время первого курса ПХТ

\begin{tabular}{lllll}
\hline Признак & \multicolumn{2}{l}{ Группа контроля } & \multicolumn{2}{l}{ Группа исследования } \\
\cline { 2 - 5 } & $\begin{array}{l}\text { степень } \\
\text { токсичности }\end{array}$ & $\begin{array}{l}\text { количество } \\
\text { случаев, \% }\end{array}$ & $\begin{array}{l}\text { степень } \\
\text { токсичности }\end{array}$ & $\begin{array}{l}\text { количество } \\
\text { случаев, \% }\end{array}$ \\
\hline Анорексия & $0-1$ & 26,9 & $0-1$ & 15,4 \\
Ухудшение аппетита & $0-2$ & 80,8 & $0-2$ & 69,3 \\
Диарея & $1-3$ & 100 & $0-2$ & 80,8 \\
Боль в животе & $1-3$ & 100 & $1-2$ & 100 \\
Стоматит & $0-4$ & 92,3 & $0-2$ & 88,8 \\
\hline
\end{tabular}


Войцицкий В.Е., Лебедева В.А., Ткачук О.А., Скуридина И.В.

Возможности нутритивной поддержки пробиотиком «Биовестин» в борьбе с гастроинтестинальными осложнениями...

Таблица 3

Распределение пациентов по степени выраженности гастроинтестинальной токсичности во время первого курса ПХТ $(M \pm m)$

\begin{tabular}{lll}
\hline Признак & Группа контроля & Группа исследования \\
\hline Анорексия & $0,29 \pm 0,18$ & $0,18 \pm 0,14$ \\
Ухудшение аппетита & $1,39 \pm 0,4$ & $0,93 \pm 0,29$ \\
Диарея & $1,75 \pm 0,29$ & $1,0 \pm 0,24^{*}$ \\
Боль в животе & $1,89 \pm 0,29$ & $1,21 \pm 0,25^{*}$ \\
Стоматит & $1,43 \pm 0,31$ & $0,93 \pm 0,24$ \\
\hline
\end{tabular}

Примеч ание : * - $p<0,05$ относительно группы контроля.

по схемам PF, TPF и FOLFOX, биологически активной добавкой «Биовестин» уменьшает гастроинтестинальную токсичность проводимого лечения и способствует оптимальному соблюдению всех этапов лечения, что особенно актуально в условиях пандемии.

Конфликт интересов. Авторы заявляют об отсутствии конфликта интересов.

\section{СПИСОК ЛИТЕРАТУРЫ}

1. The International Agency for Research on Cancer (IARC). France, 2018.

2. Travis S.P., Dinesen L. Remission in trials of ulcerative colitis: what does it mean? // Pract. Gastroenterol. 2010. Vol. 30. P. 17-20.

3. D`Haens G., Sandborn W.J., Feagan B.G. et al. A review of activity indices and efficacy end points for clinical trials of medical therapy in adults with ulcerative colitis // Gastroenterology. 2007. Vol. 132 (2). P. 763-786. DOI: 10.1053/j.gastro.2006.12.038.

4. Cosnes J., Gower-Rousseau C., Seksik P., Cortot A. Epidemiology and natural history of inflammatory bowel diseases // Gastroenterology.2011.Vol.140(6). P. 1785-1794. DOI: 10.1053/j.gastro.2011.01.055

5. Белоусова Е.А., Абдулганиева Д.И., Алексеева О.П. и др. Социально-демографическая характеристика, особенности течения и варианты лечения воспалительных заболеваний кишечника в России. Результаты двух многоцентровых исследований // Альманах клинической медицины. 2018. Т. 46, № 5. C. 445-463. DOI: 10.18786/2072-0505-201846-5-445-463.

6. Гребенкина Е.В., Гречканев Г.О. Применение нутритивной поддержки в комплексном лечении онкогинекологических больных // Нижегородский мед. журн. 2006. № 7. С. 72-76.

7. Снеговой А.В., Салтанов А.И., Манзюк Л.В., Сельчук В.Ю. Нутритивная поддержка при проведении химиотерапии // РМЖ. 2008. Т. 16, № 27. С. $1818-1824$.

8. Снеговой А.В., Салтанов А.И., Манзюк Л.В., Сельчук В.Ю. Нутритивная недостаточность и методы ее лечения у онкологических больных // Практическая онкология. 2009. Т. 10, № 1. С. 49-57.

9. Hébuterne X., Lemarié E., Michallet M. et al. Prevalence of malnutrition and current use of nutrition support in patients with cancer // J. Parenter. Enteral. Nutr. 2014. Vol. 38 (2). P. 196-204. DOI: $10.1177 / 0148607113502674$.

10. Жуков H.B. COVID-19. Новая реальность онкологической помощи. Рекомендации американской коллегии хирургов. 2020. URL: https://rosoncoweb. ru/news/oncology/2020/03/30/

11. Рак желудка. Клинические рекомендации ассоциации онкологов. 2020.

12. Опухоли головы и шеи. Клинические рекомендации ассоциации онкологов. 2020.

13. Колоректальный рак. Клинические рекомендации ассоциации онкологов. 2020.

14. NCCN Clinical Practice Guidelines in Oncology. Gastric Cancer. 2020.

15. Пачес А.И., Матякин Е.Г. Опухоли гортаноглотки. Опухоли головы и шеи: руководство. 5-е изд., доп. и перераб. М.: Практическая медицина, 2013. C. $182-185$.

16. СТСАЕ-шкала. URL: http://www.bionco.ru/tables/ common-toxicity-criteria/gastrointestinalnayatoksichnost/

Е" Поступила 01.02.2021

\section{СВЕДЕНИЯ ОБ АВТОРАХ}

Войцицкий Владимир Евгеньевич - д-р мед. наук, профессор, заведующий кафедрой онкологии ФГБОУ ВО «Новосибирский государственный медицинский университет» Минздрава России.

Лебедева Валентина Алексеевна - канд. мед. наук, доцент кафедры онкологии ФГБОУ ВО «Новосибирский государственный медицинский университет» Минздрава России.

Ткачук Ольга Анатольевна - канд. мед. наук, доцент кафедры онкологии ФГБОУ ВО «Новосибирский государственный медицинский университет» Минздрава России.

Скуридина Ирина Владимировна - канд. мед. наук, доцент кафедры онкологии ФГБОУ «Новоси- 
Войцицкий В.Е., Лебедева В.А., Ткачук О.А., Скуридина И.В.

Возможности нутритивной поддержки пробиотиком «Биовестин» в борьбе с гастроинтестинальными осложнениями...

бирский государственный медицинский университет» Минздрава России.

О бразец цитирования: Войцицкий В.Е., Лебедева В.А., Ткачук О.А., Скуридина И.В. Возмож- ности нутритивной поддержки пробиотиком «Биовестин» в борьбе с гастроинтестинальными осложнениями у онкологических пациентов в период проведения химиотерапии // Сиб. мед. вестн. 2021. № 1. С. $46-50$. 